\section{The changing microbiological and antimicrobial susceptibility profile of cerebrospinal fluid organism isolates in a teaching hospital, Tangerang, Indonesia}

\section{Abstract}

Background: Central nervous system (CNS) infections have become serious problems that contribute to morbidity and mortality in developing countries. In the recent years, antimicrobial resistance has arisen parallel with the changing trend of infectious pathogens, which resulted in the unavailability of an ideal antimicrobial agent. This study was designed to evaluate the central nervous system pathogens and their susceptibility profile using routine microbiological data.

Methods: The data of CSF culture and susceptibility testing were collected from January 2010 to August 2015. The majority of positive samples $(68 / 9 ; 68.7 \%)$ had history of neurosurgical procedures. All CSF clinical samples were immediately inoculated onto Columbia blood agar base ${ }^{\circledR}$ (Difco ${ }^{\mathrm{TM}}$ ) with sheep blood agar (5\%) and chocolate agar. CHROMagar (BBL-DifCo ${ }^{\mathrm{TM}}$ ) and Sabouraud dextrose agar were also used for isolation and presumptive identification of yeast and filamentous fungi. Identification and antimicrobial susceptibility testing of all isolates were performed by an automated method from VITEX-2 Compact $^{\circledR}$ (Biomérieux, France) in accordance with Clinical and Laboratory Standard Institute (CLSI) guideline

Results: The most common pathogens isolated were coagulase negative staphylococci (CoNS) 39/99 (39.4\%), followed by Acinetobacter baumanii 10/99 (10.1\%), Pseudomonas aeruginosa 7/99 (7.1\%), Sphingomonas paucimobilis 5/99 (5.0\%), and Aeromonas salmonocida $4 / 99$ (4.0\%). Almost of all Gram positive cocci were susceptible to
Cucunawangsih', Veronica Wiwing ${ }^{1}$, Nata PH Lugito², Vivien Puspitasari ${ }^{3}$

1 Department of Microbiology, Faculty of Medicine, University of Pelita Harapan, Indonesia

2 Department of Internal Medicine, Faculty of Medicine, University of Pelita Harapan, Indonesia

3 Department of Neurology, Faculty of Medicine, University of Pelita Harapan, Indonesia

Corresponding author:

” cucunawangsih.fk@uph.edu 
tigecycline, linezolide, vancomycin, and trimethoprim/sulfamethoxazole. Most Gram negative bacilli (GNB) were multi-drug resistant with high susceptibility level to amikacin, tigecycline, and trimethoprim/ sulfamethoxazole. The overall susceptibility testing to cephalosporins was low, ranging between $34.2 \%$ to $58.5 \%$. The susceptibility to several antifungal remained high for Candida spp. and Cryptococcus neoformans.

Conclusion: The present study demonstrates the changing pathogens trend of CNS infections along with their antimicrobial susceptibility patterns in our hospital. There is a need to implement local guidelines for empirical antimicrobial therapy and surveillance system to control the usage of antimicrobial drugs.

Keyword: antimicrobial, susceptibility, neurosurgical procedures, CNS infections

\section{Introduction}

CNS infections are life-threatening and significant causes of morbidity and mortality, especially in developing countries $[1,2]$. Bacterial infections have been known as the most common cause of the CNS infections, meanwhile fungi and mycobacteria are also frequently reported [3]. The pattern of pathogens recovered from CSF culture varies from Gram-positive cocci to multidrug-resistant Gram-negative bacteria depending on geographic region, age, co-morbidities, type of neurosurgical procedures, and site of infection $[1,4,5]$.

Neurosurgical site of infections after a neurosurgical procedure remains an important issue with overall infection rate of $0.4 \%$ to $7.7 \%$ $[3,6,7]$. Studies have shown the main organisms that cause postneurosurgical infection were non-lactose fermenting gram-negative bacteria (GNB) followed by A. baumanii, K.pneumoniae, methicillin-resistant Staphylococcus aureus (MRSA), and Candida species $[5,7,8]$.
The burden of health care associated infection in hospitals are frequently increased due to the excessive use of broad-spectrum antibiotics and because health professionals are caring less to safety precautions [8]. The development of many drug-resistant organisms, such as carbapenemresistant and methicillin/oxacillin-resistant strains, and extended-spectrum beta-lactamase (ESBL) producing bacteria may reflect the changing trend of pathogens and their antimicrobial susceptibility pattern $[9,10]$. Therefore, microbiological surveillance is important to identify the common pathogens and their antimicrobial susceptibility patterns in order to select the rational empirical antimicrobial therapy based on regional and national data to reduce the emergence of resistant organisms $[8,11,12]$.

\section{Materials and methods}

We conducted a retrospective, descriptive study using the routine microbiological data from Siloam General Hospital database. This health center is 
a private teaching hospital affiliated to Faculty of Medicine, Pelita Harapan University, located in Tangerang, Indonesia. The data of CSF cultures and antimicrobial susceptibility results were collected from January 2010 through August 2015. Data were analyzes by using SPSS 21 version.

\section{Identification and susceptibility testing of bacterial isolates}

All CSF clinical samples immediately were inoculated onto Columbia blood agar base ${ }^{\circledR}$ (Difco ${ }^{\mathrm{TM}}$ ) with sheep blood agar 5\% and chocolate agar. CHROMagar (BBL-DifCO ${ }^{\mathrm{TM}}$ ) and Sabouraud dextrose agar were used for isolation and presumptive identification of yeast and filamentous fungi. All bacterial and fungal cultures were incubated at $37^{\circ} \mathrm{C}$ for $24-48 \mathrm{hrs}$. Identification and antimicrobial susceptibility testing of all isolates was performed by an automated method from VITEX-2 Compact $^{\hat{a}}$ (Biomérieux, France) in accordance with Clinical and Laboratory Standard Institute (CLSI) guideline [13]. Escherichia coli ATCCâ 25922, Pseudomonas aeruginosa ATCCâ 27853, Staphylococcus aureus ATCCâ 29213, and Streptococcus pneumonia ATCCâ 49619 were used as control isolate for susceptibility testing. The susceptibility testing against first line TB drugs was accomplished using proportional method after cultured on Lowenstein-Jensen (LJ) medium [14].

\section{Results}

Out of the 659 CSF samples submitted, 99 (15\%) revealed growth of microorganisms, of these 87 (87.9\%) were bacterial, 8 (8.1\%) grew yeast and the rest 4 samples (4\%) grew Mycobacterium tuberculosis. The majority of positive samples 68 (68.7\%) had history of neurosurgical procedures, such as cranial operation, brain biopsies, shunt or ventricle operation, burr hole, aspiration or drainage. Other profiles of CSF organisms are shown in Table 1.
Table 1. General characteristic of 99 CSF isolated organisms

\begin{tabular}{|l|c|}
\hline $\begin{array}{c}\text { General characteristic of 99 CSF isolated } \\
\text { organisms }\end{array}$ & $\begin{array}{c}\text { Total } \\
\mathbf{n}(\%)\end{array}$ \\
\hline $\begin{array}{l}\text { Sex } \\
\text { Male }\end{array}$ & $62(62.6)$ \\
Female & $37(37.4)$ \\
\hline Age & \\
\hline $0-<1$ year & $10(10.1)$ \\
$>1-14$ year & $27(27.3)$ \\
$>14-65$ year & $56(56.6)$ \\
$>65$ year & $6(6.0)$ \\
\hline History of post neurosurgical procedures & $68(68.7)$ \\
\end{tabular}

This study demonstrated that there is a trend towards an increased number of GNB isolates over the period (2010-2015) as demonstrated in figure 1. The highest number of GNB isolates was in 2013 with 11 isolates. Over the study period, CoNS accounted for most of the isolates (39.4\%) as shown in Table 2. Among GNB isolates, $A$. baumanii was the most common (10.1\%), followed by $P$. aeruginosa $(7.1 \%)$ and Sphingomonas paucimobilis (5.1\%). The number of Cryptococcus neoformans isolates were 4, and only one isolate of MRSA was recovered (Table $\mathbf{2}$ ).

Table 3 shows that about one-third of Gram positive cocci were susceptible to a group of beta-lactam antibiotics cephalosporins, while for GNB the rate of susceptibility was higher 16/27 (59.3\%). All isolates of MRSA and CoNS (100\%) and GNB (78.8\%) were susceptible for tigecycline, respectively, and only $2.6 \%$ of CoNS isolates were resistant to vancomycin. The level of linezolide susceptibility among CoNS and other Gram positive cocci (MRSA, streptococci and enterococci) were $100 \%$ Most GNB isolates (76.7\%) were susceptible for meropenem. All Candida spp. and Cryptococcus neoformans isolates were found to be susceptible to tested antifungal drugs. 


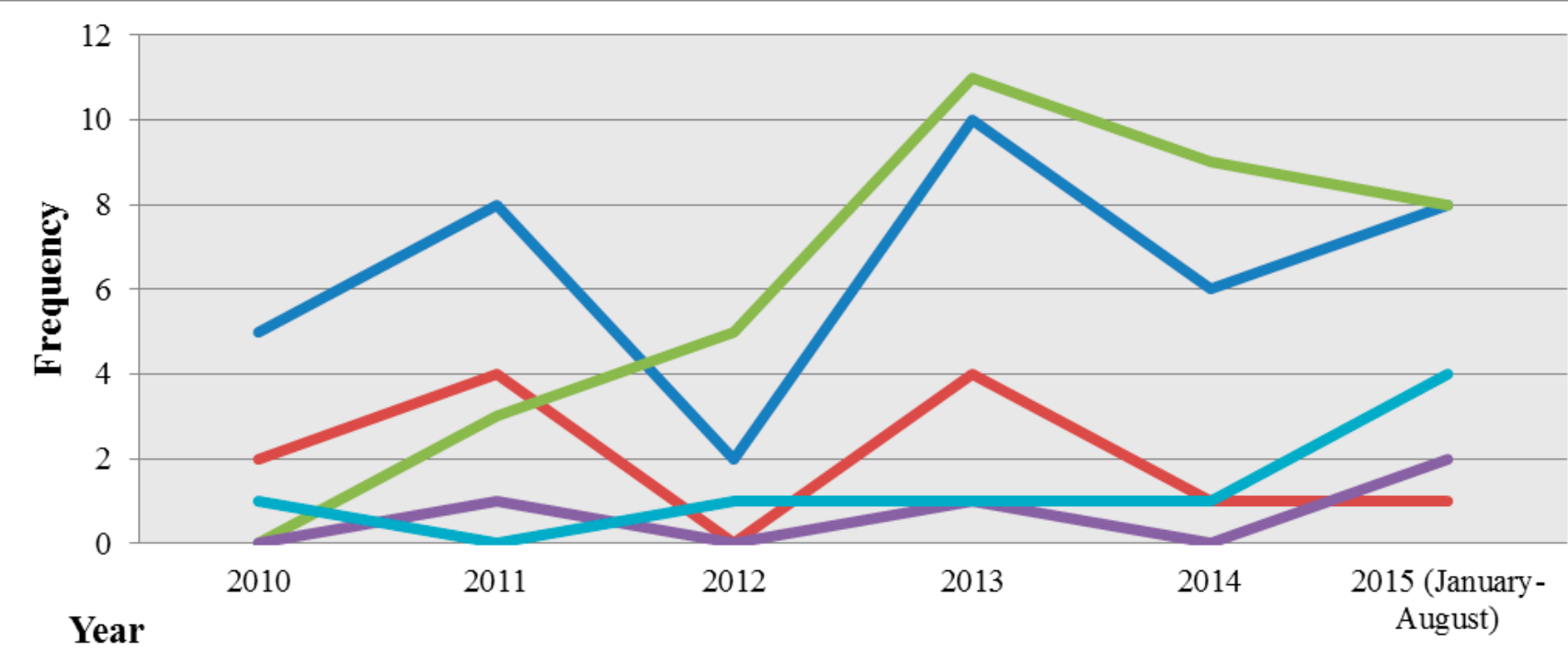

Coagulase negative staphylococci $\longrightarrow$ Other Gram $(+)$ cocci $\longrightarrow$ GNB $\longrightarrow$ M.tuberculosis $\longrightarrow$ Fungi

Figure 1. The changing trend of CSF isolates during 2010 - August 2015

\section{Discussion}

The best test to confirm CNS infection is the detection of pathogens in CSF culture $[3,15]$. This study included 68 (68.7\%) positive CSF samples which had history of neurosurgical procedures. This result is much higher than several studies noted that the incidence of intracranial postneurosurgical infection have been ranged between $0.4 \%$ to $7.7 \%[4,5,6,7]$. The profile of CSF isolates in this study showed that certain bacteria species were the predominant cause of CNS infection and was similar to other studies $[1,2,8,10]$. Coagulase negative Staphylococci was responsible for 39.4 of CSF positive culture, which was similar to a recent Iranian study [16]. The high incidence of CoNS isolates in our study may be associated with the fact that majority of patients admitted to our hospital underwent neurosurgical procedures.
The number of GNB isolates has increased especially with $A$. baumanii as a major pathogen and it is similar to studies carried out in other countries $[5,6,8]$. This study showed that the $A$. baumanii isolates were mostly multi-drug resistant, and $55.6 \%$ of these were carbapenem-resistant. Recent studies from various countries also showed that rates of carbapenem-resistant $A$. baumanii (CRAB) varied from $55 \%$ to $88 \%$ and increased particularly in association with neurosurgical infection $[5,17,18]$. The high incidence of $C R A B$ is a great concern in terms of nosocomial infection and it had been associated with serious therapeutic problem $[5,17]$. The inappropriate antibiotic usage in prophylaxis therapy, use of medical devices, length of hospitalization, and immunocompromised underlying diseases have contributed to increased morbidity and mortality due to $A$. baumanii infection [19]. Most CRAB infections led to death with mortality rate of $59.1 \%$ [17]. 
Table 2. Frequency of bacteria and yeast isolates from CSF cultures (2010-2015)

\begin{tabular}{|c|c|c|c|c|c|c|c|}
\hline \multirow[b]{2}{*}{ Type of isolate } & \multicolumn{6}{|c|}{ Year } & \multirow[b]{2}{*}{$\begin{array}{l}\text { Total } n(\%) \\
\text { isolate }\end{array}$} \\
\hline & $\begin{array}{l}2010 \\
n(\%)\end{array}$ & $\begin{array}{l}2011 \\
n(\%)\end{array}$ & $\begin{array}{l}2012 \\
n(\%)\end{array}$ & $\begin{array}{l}2013 \\
n(\%)\end{array}$ & $\begin{array}{l}2014 \\
n(\%)\end{array}$ & $\begin{array}{c}2015 \\
\text { (January- } \\
\text { August) } \\
\mathrm{n}(\%)\end{array}$ & \\
\hline CoNs ${ }^{a}$ & $5(12.8)$ & $8(20.5)$ & $2(5.1)$ & $10(25.7)$ & $6(15.4)$ & $8(20.5)$ & $39(39.4)$ \\
\hline MRSA $^{b}$ & - & $1(100.0)$ & - & - & - & - & $1(1.0)$ \\
\hline Streptococcus mitis & $1(33.3)$ & $1(33.3)$ & - & $1(33.3)$ & - & - & $3(3.0)$ \\
\hline Streptococcus mutans & - & & - & - & - & $1(100.0)$ & $1(1.0)$ \\
\hline Propionibacterium acne & $1(50.0)$ & $1(50.0)$ & - & - & - & - & $2(2.0)$ \\
\hline Enterococcus spp. & - & $1(20.0)$ & - & $3(60.0)$ & $1(20.0)$ & - & $5(5.1)$ \\
\hline Aeromonas salmonocida & - & $1(25.0)$ & - & $2(50.0$ & - & $1(25.0)$ & $4(4.0)$ \\
\hline Pseudomonas spp. & - & $2(28.6)$ & - & $2(28.6)$ & - & $3(42.8)$ & $7(7.1)$ \\
\hline Acinetobacter baumanii & - & - & $3(30.0)$ & $1(10.0)$ & $5(50.0)$ & $1(10.0)$ & $10(10.1)$ \\
\hline Burkholderia cepacia & - & - & $2(100.0)$ & - & - & - & $2(2.0)$ \\
\hline Citrobacter freundii & - & - & - & $1(100.0)$ & - & - & $1(1.0)$ \\
\hline Escherichia coli & - & - & - & $2(66.7)$ & $1(33.3)$ & - & $3(3.0)$ \\
\hline Sphingomona spaucimobilis & - & - & - & $3(60.0)$ & & $2(40.0)$ & $5(5.1)$ \\
\hline Klebsiella pneumoniae & - & - & - & - & $3(75.0)$ & $1(25.0)$ & $4(4.0)$ \\
\hline Mycobacterium tuberculosis & - & $1(25.0)$ & - & $1(25.0)$ & & $2(50.0)$ & $4(4.0)$ \\
\hline Candida spp. & $1(25.0)$ & - & $1(25.0)$ & - & & $2(50.0)$ & $4(4.0)$ \\
\hline Cryptococcus neoformans & - & - & - & $1(25.0)$ & $1(25.0)$ & $2(50.0)$ & $4(4.0)$ \\
\hline
\end{tabular}

${ }^{a}$ CoNS $=$ Coagulase negative staphylococci

${ }^{\mathrm{b}} \mathrm{MRSA}=$ methicillin-resistant Staphylococcus aureus

In our study, most Gram-positive cocci, especially CoNS were resistant to almost tested antibiotics and only susceptible to linezolid, vancomycin, tigecyclin and trimethoprim-sulfamethoxazole. This result is comparable with $100 \%$ susceptibility in previous study [10]. An earlier study in India has observed that the infection rate due to Cryptococcus neoformans was $2.93 \%$ to $3.13 \%$, and it is lower than our finding (4\%) [8]. A study conducted in Malawi had significantly higher frequency of $C$. neoformans (39.1\%) and this high prevalence was likely related to prevalence of HIV infection in their patients and which is different in our study [9], where up to twothirds of patients had neurosurgical procedures.
The limitation of this study is due to use of retrospective data, and lack of several variables such as patient's history and antibiotic treatment prior CSF sample collection which were not recorded in our database system. Therefore, this study can't distinguish between community-associated or hospital-associated CNS infection.

\section{Conclusion}

The present study demonstrates the changing pathogens trend of CNS infections along with their antimicrobial susceptibility pattern in an 
Table 3. Antimicrobial susceptibility profile of CSF isolates

\begin{tabular}{|c|c|c|c|c|c|}
\hline \multirow[t]{2}{*}{ Antimicrobial } & CoNS $^{a}$ & $\begin{array}{l}\text { Other Gram } \\
\text { positive } \\
\text { Cocci }^{\text {b }}\end{array}$ & $\mathrm{GNB}^{\mathrm{C}}$ & Yeast $^{d}$ & $\begin{array}{c}M . \\
\text { tuberculosis }\end{array}$ \\
\hline & n/total (\%) & n/total (\%) & n/total (\%) & n/total (\%) & n/total (\%) \\
\hline Ampicillin & - & $3 / 6(50.0)$ & $12 / 31(38.7)$ & - & - \\
\hline Amikacin & - & - & $27 / 33(81.8)$ & - & - \\
\hline Aztreonam & - & - & $10 / 28(35.7)$ & - & - \\
\hline Ceftazidime & $11 / 35(31.4)$ & $1 / 3(33.3)$ & 20/34 (58.8) & - & - \\
\hline Ceftriaxone & 12/37 (32.4) & $1 / 2(50.0)$ & $15 / 28(53.6)$ & - & - \\
\hline Cefotaxime & $12 / 37(32.4)$ & $2 / 3(66.7)$ & $11 / 18(61.1)$ & - & - \\
\hline Cefepime & $10 / 28(35.7)$ & 0/1 (0.0) & $17 / 28(60.7)$ & - & - \\
\hline Linezolide & $25 / 25(100.0)$ & $5 / 5(100.0)$ & - & - & - \\
\hline Meropenem & $12 / 36(33.3)$ & $1 / 4(25.0)$ & $23 / 30(76.7)$ & - & - \\
\hline Trimethoprim/Sulfamethoxazole & $22 / 36(61.1)$ & $1 / 1(100.0)$ & $15 / 26(57.6)$ & - & - \\
\hline Tigecycline & $37 / 37(100.0)$ & $7 / 7(100.0)$ & $26 / 33(78.8)$ & - & - \\
\hline Vancomycin & $37 / 38(97.4)$ & $8 / 8(100.0)$ & - & - & - \\
\hline Flucytosine & - & - & - & 5/6 (83.3) & - \\
\hline Fluconazole & - & - & - & $8 / 8(100.0)$ & - \\
\hline Amphotericin-B & - & - & - & $7 / 7(100.0)$ & - \\
\hline Voriconazole & - & - & - & $6 / 6(100.0)$ & - \\
\hline Ethambutol & - & - & - & - & $3 / 4(75.0)$ \\
\hline Isoniazid & - & - & - & - & $4 / 4(100.0)$ \\
\hline Rifampicin & - & - & - & - & $4 / 4(100.0)$ \\
\hline Streptomycin & - & - & - & - & $3 / 4(75.0)$ \\
\hline
\end{tabular}

aCoNS = Coagulase negative Staphylococci

bIncluding MRSA (1), Streptococcus mitis (3), Streptococcus mutans (1), Propionibacterium acne (2), and Enterococcus spp. (5)

${ }^{c} \mathrm{GNB}=$ Gram negative bacilli

dncluding Candida albicans (3), Candida guilliermondii (1), Cryptococcus neoformans (4)

Indonesian hospital. This finding highlights the need of local antibiotic surveillance system, guidelines to control the appropriate usage of antimicrobial regimens and selection of empirical antimicrobial therapy.

\section{Acknowledgements}

The authors express their gratitude to Siloam General Hospital in Tangerang, Indonesia who made this work realized. 


\section{References}

1. Ho Dang Trung N, Le Thi Phuong T, Wolbers M, Nguyen Van Minh H, Nguyen Thanh V, Van MP, et al. Aetiologies of Central Nervous System Infection in Viet Nam: A Prospective Provincial Hospital-Based Descriptive Surveillance Study. PLoS ONE 2012; 7(5): e37825. doi:10.1371/journal.pone.0037825.

2. Marchiori PE, Lino AMM, Machado LR, Pedalini LM, Boulos $M$, Scaff M. Neuroinfection Survey at a Neurological Ward in a Brazilian Tertiary Teaching Hospital. Clinics 2011; 66(6): 1021 1025.

3. Vengamma B, Rajguru M, Prasad BCM, Ramesh-Chandra VV.Central Nervous System Infections in the Intensive Care Unit. J Clin Sci Res 2014; 3: 106-113.

4. McClelland III S, Hall WA. Postoperative Central Nervous System Infection: Incidence and Associated Factors in 2111 Neurosurgical Procedures. CID 2007; 45: 55-59.

5. Yadegarynia D, Gachkar I, Fatemi A, Zali A, Nobari N, Asoodck M, Parsaieyan Z. Changing Pattern of Infectious Agents in Postneurosurgical Meningitis. Caspian J Intern Med.2014; 5 (3): 171-175.

6. Buang SS, Haspani MS. Risk Factors for Neurosurgical Site Infections after a Neurosurgical Procedure: A Prospective Observational Study at Hospitals Kuala Lumpur. Med J Malaysia. 2012: 67(4): 393-398.

7. Srinivas D, VeenaKumari HB, Somanna S, Bhagavatula I, Anandappa CB. The Incidence of Postoperative Meningitis in Neurosurgery: An Institutional Experience. Neurol India 2011; 59: 195-198.

8. Ravikumar R, lyothi EK, Dutta BS, Vidyasagar K, Nandan TM, Ashalatha G. Infections by Multidrug Resistant Organisms in a Neurosurgical and Neuropsychiatric Care Centre and the Changing Antimicrobial Susceptibility Patterns. JEMDS 2012; 1 (4): 444-452.

9. Maloka MH, Miller WC, Hoffman IF, Cholera R, Gilligan PH, Kamwendo D, et al. Bacterial Infections in Lilongwe, Malawi: Aetiology and Antibiotic Resistance. BMC Infectious Diseases 2012; 12: 67. http://www.biomedcentral.com/1471-2334/12/67.

10. Gitali B, Dipa B, Naba HK, Jasmin H, Sharon RR. Bacteriological Profile of Acute Meningitis: A One Year Study in a Tertiary Care Centre in Assam. Indian Journal of Public Health \& Development 2014; 5 (3): 210-214.

11. Mani R, NagarathnaS, Wasiulla R, Chandramuki A. Bacteriological Profile of Community Acquired Bacterial Meningitis: A Ten-Year Restrospective Study in a Tertiary Neurocare Centre in South India. IJMM 2007; 25 (2): 108-114.

12. van de Beck D, de Gans J, Tunkel AR, Wijdicks E F. Community Acquired Bacterial Meningitis in Adults. N Engl J Med 2006; 354: 44-53.

13. Clinical and Laboratory Standard Institute. Performance Standards for Antimicrobial Susceptibility Testing: Twentysecond Informational Supplement 2002; 32 (3): 64-65.

14. Sudiro TM, Soebandrio A, Prawoto, Sudarmono P. Resistance Pattern of Mycobacterium tuberculosis to First-Line Antituberculosis Drugs. Med J Indones 2000; 9 (3): 153-156.
15. Mengistu A, Gaeseb J, Uaaka G, Ndjavera C, Kambyambya K, Indongo L. Antimicrobial Sensitivity Patterns of Cerebrospinal Fluid (CSF) Isolates in Namibia: Implications for Empirical Antibiotic Treatment of Meningitis. Jo PPP 2013; 6: 4. doi:10.1186/2052-3211-6-4.

16. Rezaeizadeh G, Pourakbari B, Ashtiani MH, Asgari F, Mahmoudi S, Mamishi S. Antimicrobial Susceptibility of Bacteria Isolated from Cerebrospinal Fluids in an Iranian Referral Pediatric Centre, 1998-2008. Maedica J Clin Med 2012; 7 (2): 131-137.

17. Moon C, Kwak YG, Kim BN, Kim ES, Lee CS. Implications of Postneurosurgical Meningitis Caused by Carbapenem-Resistant Acinetobacter baumanii. J Infect Chemother 2013; 19: 916-919.

18. Morfin-Otero R, Alcantar-Curiel MD, Rocha MJ, AlpucheAranda CM, Santos-Preciado JI, Gayosso-Vazquez C, et al. Acinetobacter baumanii Infections in a Tertiary Care Hospital in Mexico Over the Past 13 Years. Chemotherapy 2013; 59: 57-65.

19. AbboA, Carmeli Y, Navon-Venezia S, Siegman-Igra Y, Schwaber MJ. Impact of Multi-drug Resistant Acinetobacter baumanii on Clinical Outcomes. Eur J Clin Microbiol Infect Dis 2007; 26: 793800 .

\section{Comment on this article:}
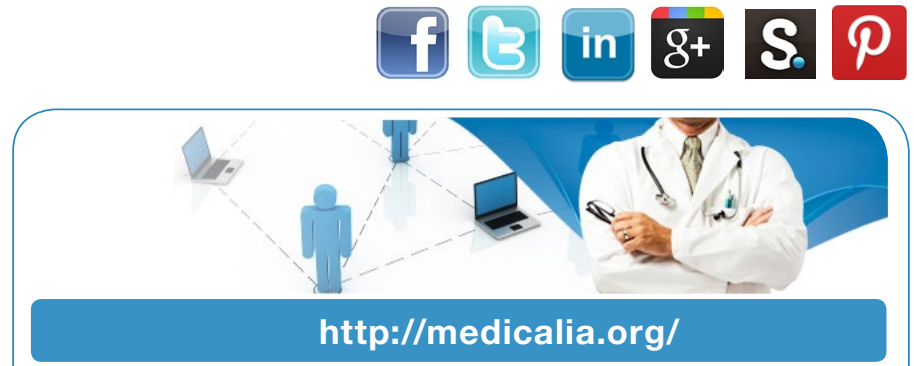

Where Doctors exchange clinical experiences, review their cases and share clinical knowledge. You can also access lots of medical publications for free. Join Now!

\section{Publish with iMedPub}

http://www.imed.pub

The Journal is an open access peer-reviewed journal that publishes scientific papers about all aspects of antimicrobials. The journal will publish original research articles, reviews, brief reports and case reports dealing with basic and clinical antibacterial agents, antiviral, antiprotozoals, antituberculuous, antifungal and antihelminthes agents.

All manuscripts must be prepared in English, and are subject to a rigorous and fair peer-review process. Accepted papers will immediately appear online.

The journal aims to advance the knowledge, attitude and the research of chemotherapy in the Arabic world in cooperation with international, national scientific and public societies as well as research centers with similar aims and objectives. 